\title{
Evaluation of the effectiveness of potato improvement in in vitro culture on optimized nutrient media
}

\author{
I.A. Gneusheva, A.Yu. Gavrilova, I.N. Gagarina, I.V. Gorkova, and I.Yu. Solokhina* \\ Federal State Budgetary Educational Institution of Higher Education "Orel State Agrarian University \\ named after N.V. Parakhin", 69 Generala Rodina Str., city of Orel, 302019, Russia
}

\begin{abstract}
Studies have been conducted on the use of an optimized Murashige-Scoog nutrient medium to obtain healthy seeds of promising potato varieties. It was found that the use of agarized modified MurashigeScoog nutrient medium with the addition of exometabolites of fungi of the genus Trichoderma lixii $1.5 \mathrm{mg} / 1$ with antimicrobial properties and the antiviral drug "Cycloferon" in a concentration of $0.01 \%$ contributes to an increase in the number of virus-free potato regenerants when the method of apical meristems and in vitro improvement is used together. The effectiveness of using the modified medium is confirmed by the following criteria: active growth of test tube potato micro-plants, which is expressed in optimal morphometric indicators on the example of the potato variety "Rosara"; the size of the isolated meristems is $10 \mathrm{~mm}$, which contributes to the output of healthy plants; the survival rate of regenerating plants. It is shown that when using the modified medium, an average of $35-50 \%$ of regenerating plants were obtained, depending on the potato variety, free from $\mathrm{M}, \mathrm{S}$ viruses.
\end{abstract}

\section{Introduction}

It is known that one of the important ensuring the maximum yield of potatoes is the planting material not infected with viruses and bacteria [1].

When potato plants are affected by pathogens, tubers are formed in the future, which are significantly inferior to healthy ones in terms of basic quality indicators [2].

To date, the production of healthy seed material is provided through an effective direction - the method of improving the apical meristem, which at the same time is associated with certain difficulties.

The problem of the method is that the isolated small explants are free of viruses, but they do not regenerate well, and large explants are simultaneously affected by viral and bacterial infection during further cultivation. These factors undoubtedly influence the yield of healthy meristems $[3,4]$.

\footnotetext{
* Corresponding author: SolohinaIrina@yandex.ru
} 
One of the most important tasks of intensive potato seed production at present is the cultivation of potatoes that are not affected by infectious pathogens, the possible minimum accumulation of pathogens due to the accelerated reproduction of healthy tubers.

The use of biotechnological methods in the laboratory for the purpose of improving promising potato varieties, as well as increasing the rate of microclone reproduction have pronounced advantages compared to clones intended for selection, which affects the reduction of time for obtaining healthy plants, and as a result, ensuring the production of mini tubers in sufficient quantity.

In many countries, the method of meristem cultivation for the production of potato tubers is most widely used, due to faster cloning and long-term storage of plants [5].

The in vitro biotechnological method for introducing meristems into the culture is important for obtaining potato micro-plants.

The use of a nutrient medium with the selected optimal composition of components is necessary for the intensive growth of meristems and for the maximum yield of regenerating plants of a virus-free nature [6].

The purpose of the work was to study the effectiveness of improving the seeds of promising potato varieties, which provides an increase in the number of virus-free regenerating plants with the combined use of the method of apical meristems and in vitro improvement on optimized nutrient media.

\section{Materials and methods}

Scientific research was carried out during 2017-2020. During the study, domestic potato varieties "Krepysh", "Rosara", "Romano", "Effect", "Resurs", "Golubizna" were used. Healthy potato tubers were selected according to visual criteria, with a positive reaction to $\mathrm{S}$ and $\mathrm{M}$ viruses (PVS and PVM) as a result of real-time PCR testing. These potato viruses often do not cause symptoms during the infection of potatoes and do not affect the yield reduction. In practice, the effect of PVS and PVM is that the loss of yield is expressed with simultaneous exposure to other potato viruses (PLRV, PVA, PVX, PVY). The culture medium of Murashige and Scoog was used (with modification), adding inhibitors of viruses and bacteria in working with meristems and regenerating plants.

At the first stage, the leaded sprouts were sterilized with a solution with chlorinecontaining components for 3-5 minutes, with washing in running water for 15 minutes. At the second stage, the sprouts were sterilized with $70 \%$ ethanol in a laminar box, followed by washing in sterile distilled water three times for 5 minutes.

In the sterile conditions of the laminar box, apical meristems were isolated on the surface of a sterile Petri dish by removing the cover leaves of the top of the sprout.

The resulting meristem was placed in a test tube on an agarized modified MurashigeScoog nutrient medium on the tip of a needle. The test tube was placed in a light room to activate the growth points.

Cutting was carried out every 20 days. 5-8 cuttings were obtained from one plant, two of which were analyzed to check for the presence of a viral infection.

In case of infection of the cuttings, the line was rejected. The virus-free material was received for microclonal reproduction.

\section{Results and discussions}

The apical meristem is understood as a cone with actively dividing cells with a diameter of 0.1-0.3 mm, free of viral material, but not protected from bacterial contamination. 
The use of Murashige-Scoog nutrient medium with hormones in its composition for the purpose of regeneration in plant explants, optimization of metabolic processes is observed, immunity and survival rate are enhanced, but there is no activation of protective mechanisms against phytopathogenic infection.

Infection with hidden and acquired phytopathogens leads to inhibition of the growth of test tube plants and even to their death.

Since nutrient media are an excellent substrate for the development of microflora of various origins, cell biology is associated with an urgent problem of contamination, which directly relates to the cultivation of plants in vitro.

To reduce contamination by bacteria, fungi and viruses, it is important to free explants from infection with phytopathogens, sterilize them with chemical preparations, and observe the conditions of sterility at the stages of introducing explants into a sterile culture.

When uninfected cells and cells that have been contaminated are cultured together, it leads to infection and death of healthy cells after several passages.

Growth stimulants, such as $\alpha$-naphthylacetic, indole butyric, gibberellic acids, as well as kinetin and 2,4 D are used as part of the Murashige-Scoog medium for in vitro.

These substances added to the nutrient medium accelerate the loss of virus viability, due to the ability to accelerate cell division and differentiation of tissue cells: the virus does not have time to penetrate the newly formed shoots before their separation.

Phenolic compounds in significant quantities contained in plants exhibit an inhibitory effect against viruses by reacting with a viral protein, oxidizing into quinones - reactive compounds.

The equivalent of virus inactivating is the amount of quinone formed.

Nucleases used to inhibit the nucleic acids of viruses are successfully used for more effective healing of plants by the apical meristem method.

Bacterial endonuclease, which cleaves the nucleic acid molecules of viruses and does not damage the cell structure, is also used to improve the health of potatoes.

Some antibiotics have an inhibitory effect on potato mosaic viruses.

Broad-spectrum antibiotics, such as lactam antibiotics - penicillin, ampicillin, cefatoxim; aminoglycosides - streptomycin, a group of tetracyclines - tetracycline, vancomycin are used during long-term cultivation to reduce infection with bacterial pathogens of cultures.

The use of antibiotics has a reducing effect on the survival of micro-plants.

To suppress the development of infectious agents, the applied concentrations of antibiotics that inhibit tissue growth are not always sufficient.

It is important to consider that the use of low-toxic antibiotics in the laboratory, used for a long time and haphazardly, can cause poisoning of plants.

A complex method of apical meristem and thermo-chemotherapy with modification of the medium by introducing preparations against viruses, enzyme preparations that inhibit RNAses, is one of the ways to improve the health of potatoes [7].

It should be noted that chemotherapeutic substances with a selective effect against viral pathogens can have a depressing effect on the plant. The long-term proposed method of recovery leads to the appearance of self-clonal variability.

Therefore, to avoid contamination of the nutrient medium, it is necessary to choose the optimal concentration of components for the elimination of viruses, bacteria and fungi, so as not to damage cell cultures and plant tissues.

In this work, for fast reproduction of meristem potatoes from lines in in vitro conditions nutrient medium Murashige and Scoog with modifications ( $\mathrm{pH}$ of 5.6 to 5.8) was used with the following composition: macrosalts $-50 \mathrm{mg} / \mathrm{l}$, microsalts $-1 \mathrm{mg} / \mathrm{l}, \mathrm{Fe}_{2} \mathrm{SO}_{4} 7 \mathrm{H}_{2} \mathrm{O} 5.0$ $\mathrm{mg} / \mathrm{l}, \mathrm{CaCl}_{2} \cdot 2 \mathrm{H}_{2} \mathrm{O}-440 \mathrm{mg} / \mathrm{l}$, thiamine $-1.0 \mathrm{mg} / 1$ pyridoxine $-1.0 \mathrm{mg} / \mathrm{l}$, meso-inositol $100 \mathrm{mg} / \mathrm{l}$, nicotinic acid $-0.5 \mathrm{mg} / \mathrm{l}$, glucose $-25 \mathrm{~g} / \mathrm{l}$, sucrose - $25 \mathrm{~g} / \mathrm{l}$, the antimicrobial 
compounds - exo-metabolites of fungi of the genus Trichoderma lixii - $1.5 \mathrm{mg} / \mathrm{l}$, agar -6 HL/1 [8], in which the antiviral preparation "Cycloferon" was added in a concentration of $0.01-0.05 \%$.

At the first stage of the work, the apical meristem zone of dividing cells was isolated from 6 varieties of potatoes infected with a viral infection, and explants were cultured on the proposed agarized modified Murashige-Scoog nutrient medium with the addition of an antimicrobial compound - exo-metabolites of fungi of the genus Trichoderma lixii, biological efficacy (in particular, the absence of phytotoxicity) of which has been confirmed in relation to phytopathogens of vegetable crops [9] and the antiviral preparation "Cycloferon".

The growth of test tube micro-plants of 6 potato varieties after two passages was compared depending on the variants of the modified nutrient media used (Table 1).

Table 1. Biometric indicators of test tube potato micro-plants obtained by the method of apical meristem and improvement in vitro.

\begin{tabular}{|c|c|c|c|c|}
\hline \multirow[b]{2}{*}{ Indicators } & \multicolumn{4}{|c|}{ Nutrient medium } \\
\hline & $\begin{array}{l}\text { Control - MS- } \\
\text { stand. medium }\end{array}$ & $\begin{array}{c}\text { MS-optim. } \\
\text { medium }\end{array}$ & $\begin{array}{l}\text { MS-optim. } \\
\text { medium with } \\
0.01 \% \text { cycloferon }\end{array}$ & $\begin{array}{c}\text { MS-optim. } \\
\text { medium with } \\
0.05 \% \text { cycloferon }\end{array}$ \\
\hline \multicolumn{5}{|c|}{ Variety "Krepysh" } \\
\hline Plant height, $\mathrm{cm}$ & 5.4 & 7.6 & 8.0 & 7.8 \\
\hline $\begin{array}{l}\text { Multiplication } \\
\text { coefficient }\end{array}$ & 3.9 & 5.6 & 5.9 & 4.5 \\
\hline \multicolumn{5}{|c|}{ Variety "Rosara" } \\
\hline Plant height, $\mathrm{cm}$ & 6.8 & 8.5 & 9.6 & 9.5 \\
\hline $\begin{array}{l}\text { Multiplication } \\
\text { coefficient }\end{array}$ & 4.3 & 5.5 & 6.9 & 5.3 \\
\hline \multicolumn{5}{|c|}{ Variety "Romano" } \\
\hline Plant height, $\mathrm{cm}$ & 5.2 & 7.4 & 7.8 & 6.9 \\
\hline $\begin{array}{l}\text { Multiplication } \\
\text { coefficient }\end{array}$ & 3.4 & 4.9 & 5.2 & 3.8 \\
\hline \multicolumn{5}{|c|}{ Variety "Effect" } \\
\hline Plant height, $\mathrm{cm}$ & 5.4 & 7.8 & 8.4 & 7.9 \\
\hline $\begin{array}{l}\text { Multiplication } \\
\text { coefficient }\end{array}$ & 3.4 & 4.7 & 5.2 & 4.8 \\
\hline \multicolumn{5}{|c|}{ Variety "Resurs" } \\
\hline Plant height, $\mathrm{cm}$ & 6.1 & 7.7 & 7.9 & 7.4 \\
\hline $\begin{array}{l}\text { Multiplication } \\
\text { coefficient }\end{array}$ & 3.7 & 4.5 & 4.9 & 4.1 \\
\hline \multicolumn{5}{|c|}{ Variety "Golubizna" } \\
\hline Plant height, $\mathrm{cm}$ & 6.9 & 8.6 & 9.4 & 9.1 \\
\hline $\begin{array}{l}\text { Multiplication } \\
\text { coefficient }\end{array}$ & 3.8 & 5.1 & 6.4 & 5.1 \\
\hline
\end{tabular}

Height of micro plants variety "Golubizna" received by the apical meristem and improvement in conditions in vitro at optimized nutrient medium with the addition of antimicrobial compounds - exo-metabolites of fungi of the genus Trichoderma lixii and antiviral preparation "Cycloferon" in a concentration of $0.01 \%$, accounted for $36 \%$ more than using standard nutrient Murashige-Scoog medium that can be said about the height of micro plants of the cultivar "Romano" and "Resurs", and their height is higher compared to the control by $5 \%$.

Therefore, it is recommended to use the proposed agarized modified Murashige-Scoog (MS) nutrient medium with the addition of an antimicrobial compound - exo-metabolites of fungi of the genus Trichoderma lixii and the antiviral preparation "Cycloferon" in a 
concentration of $0.01 \%$, it increases the reproduction coefficient and helps to reduce the periods between passages during microclonal reproduction of virus-free potato microplants.

Root growth in this variant is more active compared to the MS-standard medium by $39 \%$. The height of the plant (by $24 \%$ ) and the number of leaves (18\%) were less active. Due to the fact that a phytopathogenic infection penetrates into a growing plant through the root, when using this nutrient medium, root formation is effectively stimulated.

Consequently, according to morphometric indicators, the growth of test tube potato plants, on the example of the Rosara variety, when using the MS-o medium variant (optimized with antimicrobial and antiviral components) proceeds more actively.

We have shown that the effectiveness of improving potato plants directly depends on the size of the isolated meristems (Table 2).

Table 2. The influence of the size of meristems on the yield of healthy potato plants on the example of the "Golubizna" variety.

\begin{tabular}{|c|c|c|}
\hline \multirow{2}{*}{ Meristem size, $\mathrm{mm}$} & \multicolumn{2}{|c|}{ Output of virus-free plants, \% } \\
\cline { 2 - 3 } & $\mathrm{S}$ & $\mathrm{M}$ \\
\hline 0,10 & 18 & 98 \\
\hline 0,20 & 5 & 79 \\
\hline 0,30 & 3 & 90 \\
\hline 0,50 & 2 & 60 \\
\hline 0,70 & - & 55 \\
\hline
\end{tabular}

It was found that the yield of healthy plants isolated from meristems of the minimum size is $0.10 \mathrm{~mm}$ higher.

The use of an antiviral preparation and substances of antimicrobial origin in the nutrient medium for the purpose of improving potatoes by the apical meristem method showed a positive effect of the process of meristem survival.

The optimal number of viable meristems was revealed in the experimental version when growing in the nutrient medium with exo-metabolites of fungi of the genus Trichoderma lixii $1.5 \mathrm{mg} / \mathrm{l}$ and the antiviral preparation "Cycloferon" at a concentration of $0.01 \%$ and amounted to $76 \%$. In case of using a standard Murashige-Scoog medium on these samples, the viability was no more than $49 \%$.

The real-time PCR method established regenerating plants with the presence of latent viral infections, and that a significant number of healthy regenerating plants were obtained when exo-metabolites of fungi of the genus Trichoderma lixii $1.5 \mathrm{mg} / 1$ and the antiviral preparation "Cycloferon" at a concentration of $0.01 \%$ were introduced into the nutrient medium and amounted to $84 \%$.

When using other nutrient media, virus-free regenerating plants were obtained in a smaller amount - 56-58\%.

The use of the presented optimized nutrient media and the apical meristem method for potato improvement contributes to the survival of regenerating plants and our studies have shown a high efficiency of plant healing without the presence of viral and bacterial infection (Table 3).

Table 3. Survival rate of regenerating plants of 6 potato varieties, using the proposed method of improvement, \% (on average for 2017-2020).

\begin{tabular}{|c|c|c|c|c|}
\hline \multirow{2}{*}{ Potato variety } & \multicolumn{4}{|c|}{ Nutrient media } \\
\cline { 2 - 5 } & $\begin{array}{c}\text { Control - MS- } \\
\text { stand. medium }\end{array}$ & $\begin{array}{c}\text { MS-optim. } \\
\text { medium }\end{array}$ & $\begin{array}{c}\text { MS-optim. } \\
\text { medium with } \\
0.01 \% \text { cycloferon }\end{array}$ & $\begin{array}{c}\text { MS-optim. medium } \\
\text { with } 0.05 \% \\
\text { cycloferon }\end{array}$ \\
\hline Krepysh & 10.0 & 20.0 & 40.0 & 25.0 \\
\hline Rosara & 15.0 & 30.0 & 45.0 & 40.0 \\
\hline Romano & 10.0 & 15.0 & 35.0 & 25.0 \\
\hline
\end{tabular}




\begin{tabular}{|c|c|c|c|c|}
\hline Effect & 10.0 & 25.0 & 40.0 & 35.0 \\
\hline Resurs & 15.0 & 25.0 & 40.0 & 30.0 \\
\hline Golubizna & 20.0 & 30.0 & 50.0 & 40.0 \\
\hline
\end{tabular}

When using the agarized modified Murashige-Scoog nutrient medium with the addition of an antimicrobial compound - exo-metabolites of fungi of the genus Trichoderma lixii and the antiviral preparation "Cycloferon" in a concentration of $0.01 \%$, free from $\mathrm{M}, \mathrm{S}$ viruses and bacterial infection, an average of $35-50 \%$ of regenerating plants were obtained, depending on the potato variety.

It should be emphasized that the survival rate of regenerating plants is also largely determined by the potato genotype, which is confirmed by the data in Table 1, and as a result, the choice of nutrient medium components with the necessary concentrations for each specific variety is determined by a series of experiments.

\section{Conclusions}

Obtaining virus-free seed material by cultivating in vitro apical explants of potato seeds contributes to the effective survival of regenerating plants and shortens the regeneration period, but this method does not affect the release from extraneous bacterial infection. Sterile micro-plants are exposed to infection during the cultivation of bacterial, fungal and other types of infection.

According to the results of the conducted studies, the effectiveness of using the agarized modified Murashige-Scoog (MS) nutrient medium with the addition of the antimicrobial compound - exo-metabolites of fungi of the genus Trichoderma lixii $1.5 \mathrm{mg} / \mathrm{l}$ and the antiviral preparation "Cycloferon" at a concentration of $0.01 \%$, to increase the number of virus-free regenerating plants when using the method of apical meristems and in vitro improvement. When using this nutrient medium, the average of $35-50 \%$ of regenerating plants free from $\mathrm{M}, \mathrm{S}$ viruses were obtained, depending on the potato variety.

\section{References}

1. A.V. Korshunov, E.A. Simakov, Yu. N. Lysenko, B.V. Anisimov, A.V. Mityushkin, M.Yu. Gaitov, Dostizheniya nauki i tekhniki APK 32(3), 12-20 (2018) https://doi.org/10.24411/0235-2451-2018-10303

2. A.V. Korshunov, B.V. Anisimov, Potato seed production, quality control and certification, 291 (Russian Agricultural Academy, VNIIKH. Moscow, 2003)

3. E.V. Oves, N.A. Gaitova, V.V. Boyko, N.A. Fenina, O.S. Kolesova, Potato growing: history of development and results of scientific research: collection of scientific proc, 143-148 (FSBSI VNIIKH; Moscow, 2015)

4. Zh.V. Blotskaya, Viral, viroid and phytoplasma diseases of potatoes, 119 (Minsk: Technology, 2000)

5. H. Gong, C. Igiraneza, L. Dusengemungu, Am. J. Potato Res 96, 379-389 (2019) https://doi.org/10.1007/s12230-019-09720-z

6. E.A. Simakov, New technologies for the production of healthy starting material in elite potato seed production, 80 (M., 2000)

7. O.Yu. Antonova, O.V. Apalikova, Yu.V. Ukhatova, E.A. Krylova, O.Yu. Shuvalov, A.R. Shuvalova, T.A. Gavrilenko, Eradication of viruses in microplants of three cultivated potato species (Solanum tuberosum L., S. phureja Juz. \& Buk., S. 
stenotomum Juz. \& Buk.) using combined thermo-chemotherapy method 52 (1), 95104 (2017) doi: 10.15389/agrobiology.2017.1.95rus

8. Ninel Efimovna Pavlovskaya, Irina Alekseevna Gneusheva, Marina Aleksandrovna Polyakova, Irina Yurevna Solokhina, Patent - A01H 4/00 (2019.02); A01N 25/00 (2019.02). Microclonal propagation method of potatoes., Federal State Budgetary Institution of Higher Professional Education «Oryol state agrarian university». № 2702765 Applicat.12.09.2019, Bull. 29, 7 (2019)

9. N. Pavlovskaya, I. Gneusheva, I. Solokhina N. Ageeva, BIO Web of Conferences 21, 00021 (2020) https://doi.org/10.1051/bioconf/20202100021 